\title{
EDITORIAL
}

Epidemiology and Population Health

\section{The unparalleled rise of obesity in China: a call to action}

\author{
Erik Hemmingsson (iD ${ }^{1}$
}

Received: 25 August 2020 / Revised: 15 January 2021 / Accepted: 21 January 2021 / Published online: 19 February 2021

(c) The Author(s), under exclusive licence to Springer Nature Limited 2021

Whenever civilisations ignore a problem, they will inevitably experience increasingly louder wake-up calls, of which the year 2020 is certainly a telling example. When it comes to obesity in the Western hemisphere, mainly North America and Europe, there have been many such instances over the decades, most of them thoroughly ignored, to the countries clear detriment. A recent example from February 2020 was when obesity in the US (data from 2017 to 2018) reached $42 \%$ among adults, with severe obesity (BMI $\geq$ $40 \mathrm{~kg} / \mathrm{m}^{2}$ ) approaching double digits at $9 \%$ [1]. While European nations are behind the US, the same upward trajectory is certainly present, especially in socially vulnerable populations $[2,3]$. The corresponding numbers in the Eastern hemisphere, mainly Asia, are generally lower still, but this appears to be changing. In this issue of the journal Ma et al. [4], convincingly show that China is in the midst of a severely alarming increase in obesity, particularly abdominal obesity. When these increases are combined with the sheer size of China's population, we are likely witnessing an unparalleled development, at least in scope.

Using a series of cross-sectional surveys between 1993 and 2015, including $~ 70,000$ adults from different regions of China, Ma et al. calculated overall and subgroup trends, using standardisation to account for variations between surveys in important prognostic variables, such as age, gender, etc. They also carried out extensive sensitivity analyses to test the robustness of their findings. While there are always limitations in using multiple crosssectional surveys to study population trends, which the authors discuss and acknowledge, we can nevertheless be reasonably confident that the findings are both valid and representative of the development of obesity and abdominal obesity in Chinese adults since 1993. A particularly

Erik Hemmingsson

erik.hemmingsson@gih.se

1 Department of Physical Activity and Health, The Swedish School of Sport and Health Sciences, Stockholm, Sweden strong point of the study was the inclusion of waist circumference data.

The authors found that obesity (using the WHO cut-off of $\mathrm{BMI} \geq 27.5 \mathrm{~m} / \mathrm{kg}^{2}$ ) increased from $4.2 \%$ in 1993 to $15.7 \%$ in 2015 . At the same time abdominal obesity ( $\geq 90 \mathrm{~cm}$ for men and $\geq 80 \mathrm{~cm}$ for women) increased from $20.2 \%$ to $46.9 \%$. A simple visual inspection of the distribution of BMI and waist circumference in 1993 versus 2015 tells a very stark picture indeed (Fig. 1), with a flattening and marked shift to the right, especially for waist circumference.
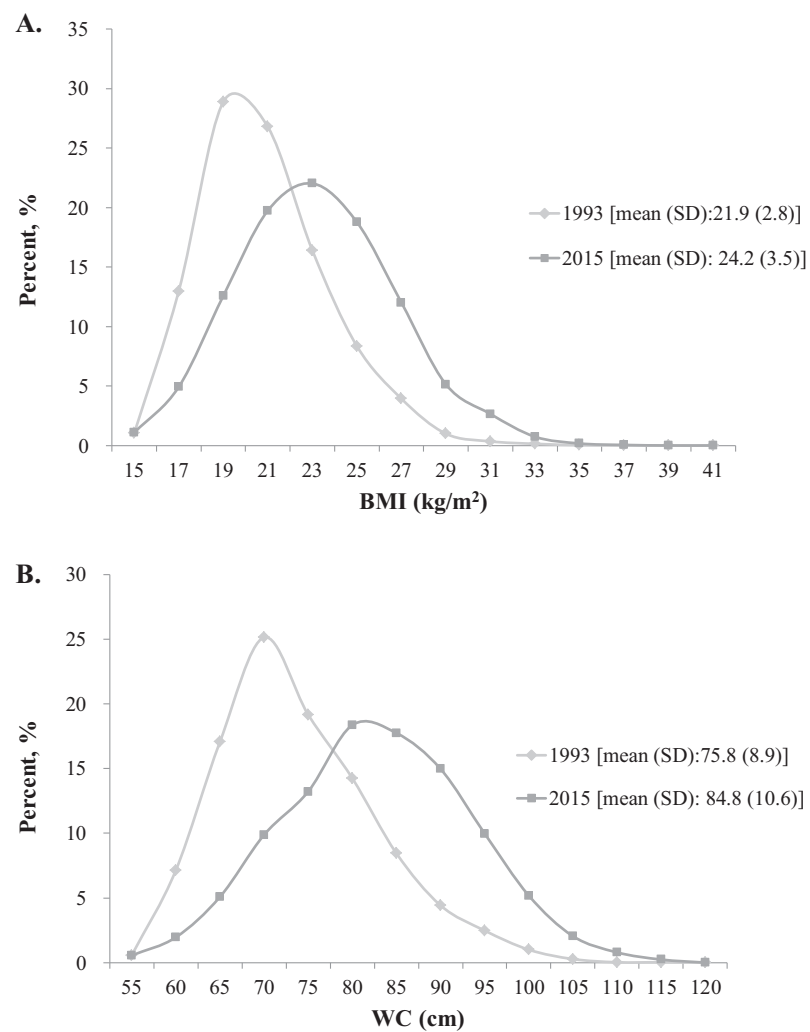

Fig. 1 Changes in the distribution of $\mathbf{A}$ body mass index and $\mathbf{B}$ waist circumference in Chinese adults between 1993 and 2015. 
Line graphs of the prevalence rates at the different survey time points paint a similarly bleak picture: a clear and drastic increase, with no discernible signs of a slowdown, mirroring the developments seen in the US and elsewhere $[1,2]$. Rudimentary arithmetic indicate an annual increase for obesity of just over 0.5 percentage points ([15.7-4.2]/22 y) and 1.2 percentage points ([46.9-20.2]/22) for abdominal obesity. Assuming a continued linear increase, China can expect over $20 \%$ obesity and a staggering $59 \%$ abdominal obesity within a decade. The dangers of wide-spread type- 2 diabetes and cardiovascular disease loom very large indeed.

While obesity aetiology is multifactorial, including many aspects that are still not well understood, there are also likely to be underlying factors that are specific to China, such as previous famines and social policies. But the main overall driver is likely to be China's exceptionally rapid economic growth [5]. While this has created more prosperity and reduced poverty, the flipside has been an equally rapid nutrition transition [6], away from more traditional and balanced foods to a gradual introduction of ultraprocessed junk food products [4, 6]. Such changes in our diet are now increasingly being implicated in weight gain and obesity [7], as well as many other chronic diseases [8].

The findings of Ma et al. are therefore a stark warning to China and other developing countries. Individuals will always have a clear responsibility for their health, but empirical evidence from the West and elsewhere show that this will not be enough. Neither should we put any stock in requests to the multinational food industry to self-regulate, something they have no financial interest in. While successful obesity prevention will obviously require many changes to our societies, not just the food environment, a sensible option is nevertheless to start using policy measures to curb consumption of obesogenic food products, i.e. an initial focus on intermediary outcomes.

Much of the political disinterest in implementing such policies, at least in the West [9], can probably be traced to the public opinion that obesity is self-inflicted, and that individuals with obesity lack character and will-power. This is a flawed narrative that is now facing increasing and much welcome resistance from academics, physicians and patient groups [10]. Another mental barrier to action is the nannystate argument. This holds more merit, since we do not want governments to be overly authoritarian, but rather to act in a way that facilitates healthy choices, especially for socially vulnerable groups [3]. A key issue will be to make healthy food options cheaper and more available, and also to conduct rigorous scientific evaluations on the effectiveness of such policies.

China and many other developing countries now face important choices. They can choose a path similar to the West, where obesity has been largely ignored. Or they can choose a path where sound and scientifically driven policies are used to balance continued economic prosperity with the clear ambition to facilitate healthy lifestyles.

\section{References}

1. Hales CM, Carroll MD, Fryar CD, Ogden CL. Prevalence of obesity and severe obesity among adults: United States, 2017-2018. NCHS Data Brief. 2020;360:1-8.

2. Hemmingsson E, Ekblom O, Kallings LV, Andersson G, Wallin $\mathrm{P}$, Soderling J, et al. Prevalence and time trends of overweight, obesity and severe obesity in 447,925 Swedish adults, 1995-2017. Scand J Public Health. 2020.1403494820914802.

3. Magnusson M, Sorensen TI, Olafsdottir S, Lehtinen-Jacks S, Holmen TL, Heitmann BL, et al. Social inequalities in obesity persist in the Nordic region despite its relative affluence and equity. Curr Obes Rep. 2014;3:1-15.

4. Ma S, Xi B, Yang L, Sun J, Zhao M, Bovet P. Trends in the prevalence of overweight, obesity, and abdominal obesity among Chinese adults between 1993 and 2015. Int J Obes (Lond). 2021;45:427-37.

5. Fox A, Feng W, Asal V. What is driving global obesity trends? Globalization or "modernization"? Global Health. 2019;15:32.

6. Du SF, Wang HJ, Zhang B, Zhai FY, Popkin BM. China in the period of transition from scarcity and extensive undernutrition to emerging nutrition-related non-communicable diseases, 1949-1992. Obes Rev. 2014;15 (Suppl 1):8-15.

7. Hall KD, Ayuketha A, Brychta R, Cai H, Cassimatis T, Chen KY, et al. Ultra-processed diets cause excess calorie intake and weight gain: an Inpatient Randomized Controlled Trial of ad libitum food intake. Cell Metab. 2019;32:690.

8. Chen X, Zhang Z, Yang H, Qiu P, Wang H, Wang F, et al. Consumption of ultra-processed foods and health outcomes: a systematic review of epidemiological studies. Nutr J. 2020;19:86.

9. Lyn R, Heath E, Dubhashi J. Global implementation of obesity prevention policies: a review of progress, politics, and the path forward. Curr Obes Rep. 2019;8:504-16.

10. Rubino F, Puhl RM, Cummings DE, Eckel RH, Ryan DH, Mechanick JI, et al. Joint international consensus statement for ending stigma of obesity. Nat Med. 2020;26:485-97. 